Original scientific paper

\title{
AMOS-BASED RISK FORECAST OF MANUFACTURING SUPPLY CHAIN
}

\author{
Wan, Y. M. \\ School of Economics and Management, Northeast Agricultural University, Harbin 150030, China \\ E-Mail: YumingWan@neau.edu.cn (Corresponding author)
}

\begin{abstract}
Manufacturing supply chain is vulnerable to various risks, because of its complex network structure, as well as the strong sensitivity of manufacturing to the dynamic market changes. Therefore, the management of supply chain risks has become the focus of manufacturers. To help Chinese enterprises reduce or eliminate supply chain risks, this paper puts forward several hypotheses and a risk forecast model for manufacturing through theoretical analysis. By the Amos method, the hypotheses were tested through path analysis with empirical data. Finally, an artificial neural network (ANN) was adopted to verify the effectiveness of the proposed Amos model. The study provides the reference for preventing supply chain risks and promoting the healthy development of manufacturing enterprises.

(Received in October 2020, accepted in January 2021. This paper was with the author 1 month for 1 revision.)
\end{abstract}

Key Words: Manufacturing Supply Chain, Risk Forecast, Modelling, Amos, Artificial Neural Network (ANN)

\section{INTRODUCTION}

Economic globalization has intensified market competition, creating an increasingly turbulent market environment. Instead of core enterprises, the supply chain becomes the main subject of enterprise competition. As a result, an enterprise could gain a competitive edge through proper management of the supply chain.

As the supply chain evolves, however, the supply chain structure is more and more complex, giving rise to prominent problems like information distortion and lag. Meanwhile, enterprises are faced with challenges like unstable business environment, high expectation of personalized services, and short product lifecycle. These trends, coupled with the influence of political, economic, cultural, and legal factors, pose many external and internal threats to the supply chain.

Against the above backdrop, the management of supply chain risks is now a research hotspot. The key of supply chain management lies in analysing supply chain risks, using the theory and method of risk management. Nonetheless, relatively few scholars have tackled the risks of manufacturing supply chain. Most researchers aim to extend the theory and technique of risk management to supply chain management.

Typically, risk management covers four basic stages: risk identification, risk assessment, risk decision-making and management, and risk monitoring [1]. Among them, risk identification is the premise of supply chain risk management. Based on the Supply Chain Operations Reference (SCOR) model, Jin [2] established an index system for identifying supply chain risks. Neiger et al. [3] put forward a method to identify supply chain risks, which centres on the value chain. According to the features of supply chain risk factors, Wang and Zhang [4] proposed an assessment method for supply chain risks based on extended matter-element model. Xu and Tian [5] identified supply chain risks of manufacturers based on vector autoregression (VAR) model. Peng and Yao [6] constructed a multi-factor evaluation index system of supply chain risks and conducted empirical research through multi-level fuzzy comprehensive evaluation (FCE). Zhang and Chen [7] created a six-aspect risk identification framework by casual analysis and stratified analysis. Through cluster analysis, Thun and 
Hoenik [8] found that the internal risks of supply chain are more harmful and more likely to occur than the external risks. Wang et al. [9] established a supply chain risk management model based on the expected loss method. Jiang et al. [10] combined FCE and artificial neural network (ANN) into a comprehensive evaluation model for supply chain risks. With the aid of backpropagation neural network (BPNN), Pan et al. [11] evaluated the importance of potential risk factors in car making supply chain, and revealed that the overall risk of the supply chain is mainly affected by the strategic risk of the supplier, as well as the production risk, accident risk, and financial risk of the manufacturer [12].

In general, there are many strategies to identify, evaluate, and model supply chain risks. However, it would be simpler, and more accurate to realize the multiple objectives with the ANN. Based on the supply chain theory, this paper constructs a forecast model for supply chain risks of the manufacturing industry. Combined with the survey data on some Chinese manufacturers, the authors forecasted and simulated the supply chain risks. The research findings provide an empirical basis and a theoretical reference for China's manufacturing industry to reduce or eliminate supply chain risks.

\section{RISK ANALYSIS AND THEORETICAL MODELLING}

China's manufacturing industry is relatively backward with a low added value. Over the years, the simple supply-demand relationship between manufacturers and the upstream and downstream links of the manufacturing supply chain has become increasingly complex. Every link needs close cooperation to maintain the normal operation of the complex production system.

\subsection{Relationship risk}

Supply chain risk is a transitory structural risk, which stems from supply-demand imbalance and supply/demand satisfaction in the supply chain. From the angle of internal links, the supply chain operation might have uncertain risks in the links of supply, production, logistics and demand. In the meantime, the supply chain is deeply affected by external factors like policies, natural disasters, and emergencies.

The partnership between supply chain members is a double-edged sword. While enhancing the operating efficiency, it makes the supply chain structure more vulnerable, due to the complex cooperation network between supply side and demand side. A good partnership in the supply chain can enable suppliers to achieve economies of scale, and the demand side to obtain high-quality and timely supplies. This relationship could be consolidated, if supply and demand of both sides are stable [13].

Moreover, good partnerships are built on trust and commitment. The coordination and dependence of partners can contribute to the success of partnership. Ma [14] introduced game theory to analyse the trust relationship between supply chain partners, pointing out that the trust relationship between supply chain partners is the basis of cooperation. Therefore, even if supply chain partners achieve win-win cooperation, there are still potential risks in supply-demand relationship. Besides, the quality risk of supply chain structure might bring many other risks, exerting an intermediary effect.

Therefore, this paper proposes the following hypotheses:

H1: The relationship risk of supply chain is the fundamental and intermediary risk in the supply chain.

H11: The relationship risk of supply chain is mainly affected by the degree of trust of the enterprise to the other party, the reputation of the enterprise, and the coincidence degree of development strategies of the two enterprises.

Considering the impact of external environment on the supply-demand structure of supply chain, Tang [15] discussed the risk factors of supply chain partnership of carmakers, and 
regarded the external environmental risk as an important inducer of relationship risk. Zhang [16] stated that the external environment positively affects the quality of supply chain relationship, which in turn promotes the reverse supply chain management. Thus, the following hypothesis was presented:

H12: The change of external environment directly affects the supply chain structure, and then causes the relationship risk.

\subsection{Product quality risk}

In manufacturing supply chain, the business activities related to products in the early, middle, and later phases are part of the operations of the supply chain. Product quality risk may arise from the quality of supply-demand relationship in the supply chain.

Song et al. [17] suggested that Supply Chain Relationship Quality (SCRQ) means the extent to which both parties of the supply chain actively engage in long-term cooperation. Zhang [18] held that the quality of supply-demand relationship is a comprehensive manifestation of the strength of the relationship between the two supply chain manufacturers in long-term cooperation. Zhang [19] defined the quality of supply chain relationship as the perception of the main bilateral relationship in the supply chain based on the merits and defects, as per specific standards at different stages and levels. Xia and Zhang [20] proved that new product development can be bolstered by improving the relationship quality between supply chain enterprises. Fynes et al. [21] demonstrated that the quality of supply-demand relationship directly promotes supply chain performance, as well as product quality. Thus, the following hypothesis was presented:

$\mathrm{H} 2$ : The relationship risk affects the product quality risk in the supply chain.

In practice, the product quality is highly uncertain, owing to the immaturity of multiple links (e.g., design, research and development, production, and process flow), and the imperfect management of such links as procurement, production, storage, and transportation. The product quality risk that ensues could bring huge economic losses to enterprises [22].

In the supply chain, the product quality risk is a systematic risk, rather than a simple concept within a single enterprise. The product quality risk in the supply chain is not only related to the information asymmetry in the transactions of nodal enterprises, but also affected by the supply chain structure [23]. In fact, this risk covers both the quality defects of the product, and the risks of product supply model and product service.

Jiang et al. [24] gave the basic definition of supply chain quality risk, and divided the risk into credit quality risk, technical quality risk, and demand quality risk. Considering the influencing factors of product quality, this paper divides the product quality risk into three aspects: supplier quality risk, supply-demand information flow quality risk, and production quality risk. Moreover, the following hypothesis was presented:

$\mathrm{H} 21$ : The most significant product quality risk is the production quality risk.

\subsection{Market demand risk}

The fluctuations of global economy and refinement of consumer demand have increased the uncertainty of the market demand of the supply chain, resulting in great challenges to corporate decision-making on production and supply-demand. Besides, any change in the demand of a supply chain member is bound to affect the related members. Hence, the manufacturing supply chain faces a huge risk of market volatility.

In a supply chain, demand uncertainty is the most direct impact from external factors [25]. Under uncertain demand, Yao et al. [26] designed the revenue sharing contract for a twoechelon supply chain composed of a supplier and two competitive retailers. Yu et al. [27] optimized the supply chain response strategy for demand changes under emergencies. Klibi and 
Martel [28] proposed a risk modelling method for evaluation and design of supply chain network under uncertainty.

Without considering natural disasters, demand uncertainty in the supply chain can be roughly attributed to two sources: the change of external industrial policies and market rules; the information lag and distortion caused by information asymmetry and incompleteness in the supply chain. Specifically, information asymmetry biases customer demand and induces time delay; incomplete information makes it hard for supply chain enterprises to make correct decisions in time. These two factors exert a profound impact on the fluctuation of market and give birth to relationship risk and product quality risk of the supply chain.

Therefore, this paper proposes the following hypotheses:

H3: Market demand risk induces relationship risk and product quality risk.

$\mathrm{H} 31$ : The relationship risk and product quality risk enhance market demand risk, because they affect the market recognition of the enterprises and industry of the supply chain.

\subsection{Correlations between risk dimensions}

Through the above analysis, the correlations between the three risk dimensions are displayed in Fig. 1.

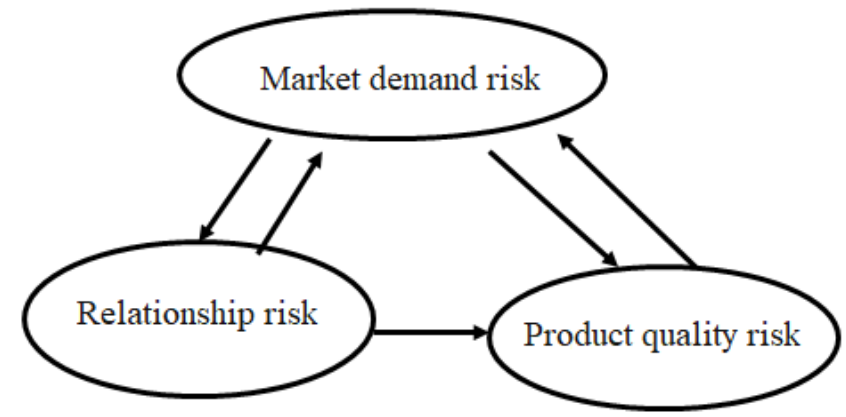

Figure 1: Correlations between the three risk dimensions.

Based on the hypotheses, the authors designed a questionnaire, and analysed the risk factors and their mutual influence, laying the basis for supply chain risk forecast.

\section{METHODOLOGY}

Firstly, SPSS22.0 was adopted for descriptive analysis, and a risk forecast model was established through structural equation modelling (SEM). The SEM is a popular way to establish, estimate, and test causality models, which contain both observable and latent variables. Initially used in psychology, structural equation has now been widely applied in economic management. To clarify the correlations and mutual influence of supply chain risk factors, this paper builds up an SEM model for risk forecast based on the identified risk factors.

Secondly, the BPNN, a typical ANN, was introduced to simulate and verify the Amos risk forecast model. The ANN is a technique that spans across different disciplines, such as biology, computer science, and mathematics. It is extensively applied in machine learning, and target recognition $[29,30]$. The ANN, composed of artificial nodes that simply and mimic biological neurons, simulates how the biological neural system responds to specific objects [31]. Through self-learning, the network can improve itself by weight adjustment as per the changes of the external environment. When it comes to risk forecast and simulation, the ANN performs well in the response to and fitting of the complex relationship between risk factors, due to its selflearning ability, adaptivity, and calculation efficiency. As a representative ANN, the BPNN is particularly popular in data identification and classification, network intrusion detection, risk prediction and simulation, thanks to its ability to approximate any complex nonlinear mapping 
with arbitrary precision, as well as its strong generalization ability, high robustness, and good fault tolerance [32].

\section{RISK FORECAST MODELLING OF MANUFACTURING SUPPLY CHAIN}

\subsection{Composition of risk indices}

According to the analysis in section 2, the risk sources of manufacturing supply chain are divided into three dimensions. The measuring indices of each dimension are presented in Fig. 2.

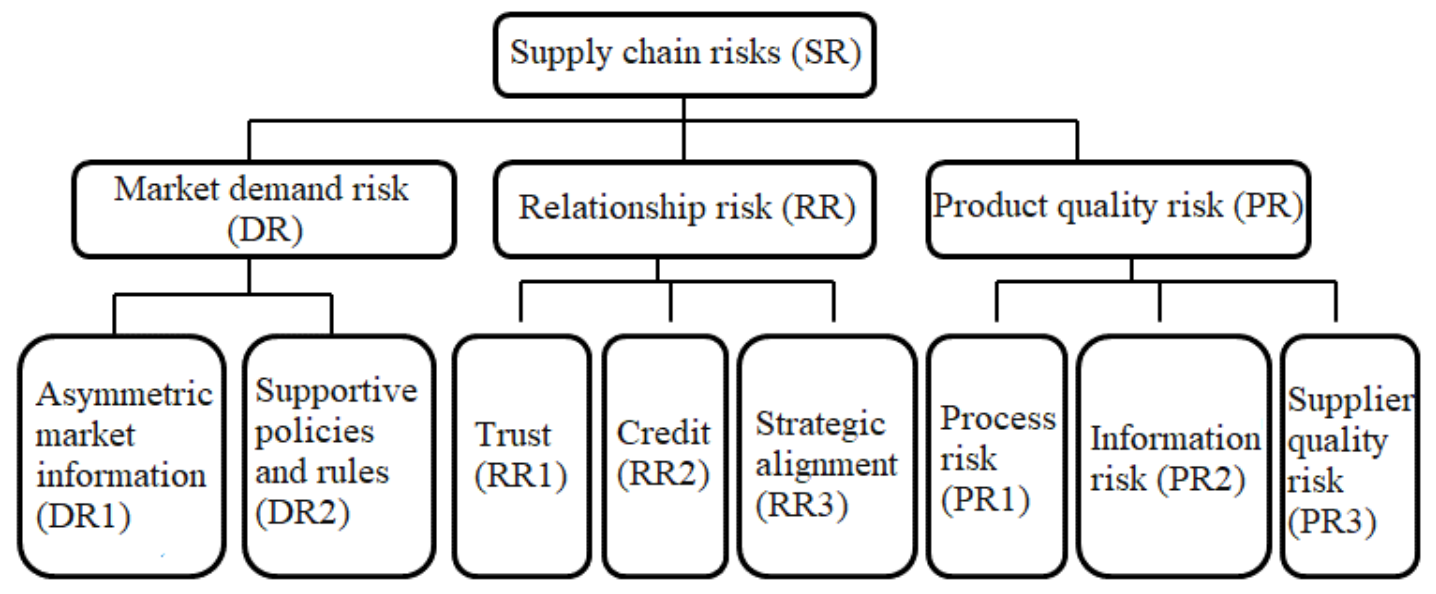

Figure 2: Risk composition of supply chain.

Based on the risk dimensions and indices, a questionnaire was designed, and distributed to 126 manufacturers via third-party questionnaire survey companies in the Yangtze River Delta and Pearl River Delta, both of which are advanced manufacturing bases in China.

\subsection{Descriptive analysis}

During the questionnaire survey, the answers to the questions were relatively accurate, for all respondents are typical manufacturers. Thus, each risk index in Fig. 2 can be measured by the answers to the corresponding question. A total of 120 valid questionnaires were collected. The total number is sufficient to make a robust descriptive analysis. Among them, 100 questionnaires were used for modelling, and the remaining 20 for simulation.

Tables I and II show the results of reliability and validity tests on 100 questionnaires, respectively.

Table I: Results of reliability test.

\begin{tabular}{|c|c|c|c|}
\hline Item & $\begin{array}{c}\text { Corrected item-total correlation } \\
\text { (CITC) }\end{array}$ & $\begin{array}{c}\text { Cronbach's alpha of the deleted } \\
\text { item }\end{array}$ & $\begin{array}{l}\text { Cronbach's } \\
\text { alpha }\end{array}$ \\
\hline DR1 & 0.411 & 0.844 & \multirow{8}{*}{0.844} \\
\hline DR2 & 0.318 & 0.855 & \\
\hline RR1 & 0.648 & 0.816 & \\
\hline RR2 & 0.607 & 0.822 & \\
\hline RR3 & 0.661 & 0.814 & \\
\hline PR1 & 0.626 & 0.819 & \\
\hline PR2 & 0.678 & 0.811 & \\
\hline PR3 & 0.671 & 0.813 & \\
\hline
\end{tabular}


As shown in Table I, the standardized Cronbach's alpha was 0.841 , greater than 0.8 . Hence, the survey data are sufficiently reliable for further analysis, and none of the items in the questionnaire should be deleted.

As shown in Table II, the KMO measure of sampling adequacy fell between 0.7 and 0.8 , a sign of good validity.

Table II: Results of validity test.

\begin{tabular}{|c|c|c|}
\hline \multicolumn{3}{|c|}{ Kaiser-Meyer-Olkin (KMO) and Bartlett's test } \\
\hline \multicolumn{2}{|c|}{ KMO measure of sampling adequacy } & 0.789 \\
\hline \multirow{3}{*}{ Bartlett's test of sphericity } & Approx. Chi-square & 379.408 \\
\cline { 2 - 3 } & $d f$ & 28 \\
\cline { 2 - 3 } & Sig. & 0 \\
\hline
\end{tabular}

\subsection{Amos-based forecast of supply chain risks}

The risk factors of the supply chain were modelled on Amos 22.0.

(1) Fitness analysis

Table III: Common fitness indices.

\begin{tabular}{|l|c|c|c|c|c|c|c|c|}
\hline Common index & $p$ & $\chi^{2} / d f$ & $G F I$ & $R M S E A$ & $R M R$ & $C F I$ & $N F I$ & $N N F I$ \\
\hline Judgement criterion & $>0.05$ & $<3$ & $>0.9$ & $<0.10$ & $<0.05$ & $>0.9$ & $>0.9$ & $>0.9$ \\
\hline Value & 0.015 & 1.882 & 0.934 & 0.094 & 0.055 & 0.959 & 0.919 & 0.933 \\
\hline
\end{tabular}

Note: $x^{2} / d f, G F I, R M S E A, R M R, C F I, N F I, N N F I$ are short for: chi-square / degrees of freedom, goodness of fit, root mean square error of approximation, root mean square, comparative fit index, normed-fit index, and non-normed fit index, respectively.

Table IV: Estimated residuals.

\begin{tabular}{|c|c|c|c|c|c|}
\hline \multicolumn{7}{|c|}{ Estimated residuals } \\
\hline Item & Coef. & Std. error & $z$ & $p$ & Std. estimate \\
\hline DR1 & 0.336 & 0.145 & 2.321 & 0.02 & 0.448 \\
\hline DR2 & 0.584 & 0.128 & 4.562 & 0 & 0.664 \\
\hline RR1 & 0.241 & 0.054 & 4.431 & 0 & 0.259 \\
\hline RR2 & 0.146 & 0.045 & 3.264 & 0.001 & 0.183 \\
\hline RR3 & 0.368 & 0.063 & 5.816 & 0 & 0.399 \\
\hline PR1 & 0.314 & 0.066 & 4.767 & 0 & 0.337 \\
\hline PR2 & 0.275 & 0.075 & 3.678 & 0 & 0.248 \\
\hline PR3 & 0.458 & 0.081 & 5.662 & 0 & 0.441 \\
\hline DR & 0.414 & 0.166 & 2.487 & 0.013 & 1 \\
\hline RR & 0.609 & 0.125 & 4.863 & 0 & 0.886 \\
\hline PR & 0.35 & 0.088 & 3.984 & 0 & 0.565 \\
\hline
\end{tabular}

The SEM has many fitness indices. It is difficult to satisfy the criteria of all indices simultaneously. After more than 20 model adjustments, the values of common indices in Table III were basically in line with the standard values. In general, our model has good accuracy and validity.

After the model had been fitted, the estimated residuals of all items were obtained (Table IV).

Residual, the deviation between the estimated value and the actual value, measures the regression effect. As shown in Table IV, the data error was relatively small, suggesting that our model can be interpreted. 
(2) Path analysis of hypotheses

SEM includes two kinds of relationships, namely, structural influence relationship and measurement relationship. Table $\mathrm{V}$ sums up the structural influence relationship between factors or scales.

Table V: Influence paths between factors.

\begin{tabular}{|c|c|c|c|c|c|c|c|}
\hline Factor & $\rightarrow$ & Factor & $\begin{array}{c}\text { Nonstandard path } \\
\text { coefficient }\end{array}$ & $S E$ & $z$ & $p$ & $\begin{array}{c}\text { Standard path } \\
\text { coefficient }\end{array}$ \\
\hline $\mathrm{DR}$ & $\rightarrow$ & $\mathrm{RR}$ & 0.592 & 0.085 & 2.171 & 0.030 & 0.338 \\
\hline $\mathrm{DR}$ & $\rightarrow$ & $\mathrm{PR}$ & -0.104 & 0.11 & 2.235 & 0.025 & 0.354 \\
\hline $\mathrm{RR}$ & $\rightarrow$ & $\mathrm{PR}$ & 0.606 & 0.137 & 3.905 & 0.000 & 0.450 \\
\hline
\end{tabular}

As shown in Table $\mathrm{V}$, the standard path coefficient about the influence of DR on RR was $0.338>0$, which is significant on the level of $0.05(z=2.171, p=0.030<0.05)$. Thus, DR significantly promotes RR. The standard path coefficient about the influence of DR on PR was $0.354>0$, which is significant on the level of $0.05(z=2.235, p=0.025<0.05)$. Thus, DR significantly promotes PR. The standard path coefficient about the influence of RR on PR was $0.450>0$, which is significant on the level of $0.01(z=3.905, p=0.000<0.01)$. Thus, RR significantly promotes PR.

The above results show that hypotheses $\mathrm{H} 3$ and $\mathrm{H} 12$ are valid: DR not only affects RR, but also directly affects PR. Meanwhile, DR indirectly affects PR via RR. In addition, RR directly affects $P R$, and DR indirectly affects $P R$ via $R R$. That is, $R R$ has a partial mediating role. This further shows that $\mathrm{H} 1$ and $\mathrm{H} 2$ are valid, but $\mathrm{H} 31$ does not hold.

Table VI: Measurement relationships.

\begin{tabular}{|c|c|c|c|c|c|c|c|}
\hline Index & $\rightarrow$ & Factor & Nonstandard coefficient & $S E$ & $z$ & $p$ & Standard coefficient \\
\hline DR1 & $\rightarrow$ & DR & 1 & - & - & - & 0.743 \\
\hline DR2 & $\rightarrow$ & DR & 0.846 & 0.294 & 2.874 & 0 & 0.58 \\
\hline RR1 & $\rightarrow$ & RR & 1 & - & - & - & 0.861 \\
\hline RR2 & $\rightarrow$ & RR & 0.976 & 0.091 & 10.704 & 0 & 0.904 \\
\hline RR3 & $\rightarrow$ & RR & 0.898 & 0.099 & 9.058 & 0 & 0.775 \\
\hline PR1 & $\rightarrow$ & PR & 1 & - & - & - & 0.814 \\
\hline PR2 & $\rightarrow$ & PR & 1.159 & 0.131 & 8.818 & 0 & 0.867 \\
\hline PR3 & $\rightarrow$ & PR & 0.968 & 0.124 & 7.784 & 0 & 0.748 \\
\hline
\end{tabular}

Table VI reflects the relative importance between risk factors. Since the effect of PR1 on PR was not the largest, H21 does not hold. The composition of RR indicates that H11 is valid. In addition, DR1 was more important than DR2, suggesting that symmetric real-time market information is the most important factor, that is, the sensitivity and responsiveness of enterprises to the market.

(3) Risk forecast model

Fig. 3 shows our SEM forecast model for supply chain risks.

Fig. 3 indicates that our theoretical model is appropriate, giving a clear picture of the index weights, the mutual influence between factors, and the influence intensity. Next, the model was subject to a simulation based on empirical data to illustrate the research conclusions. 


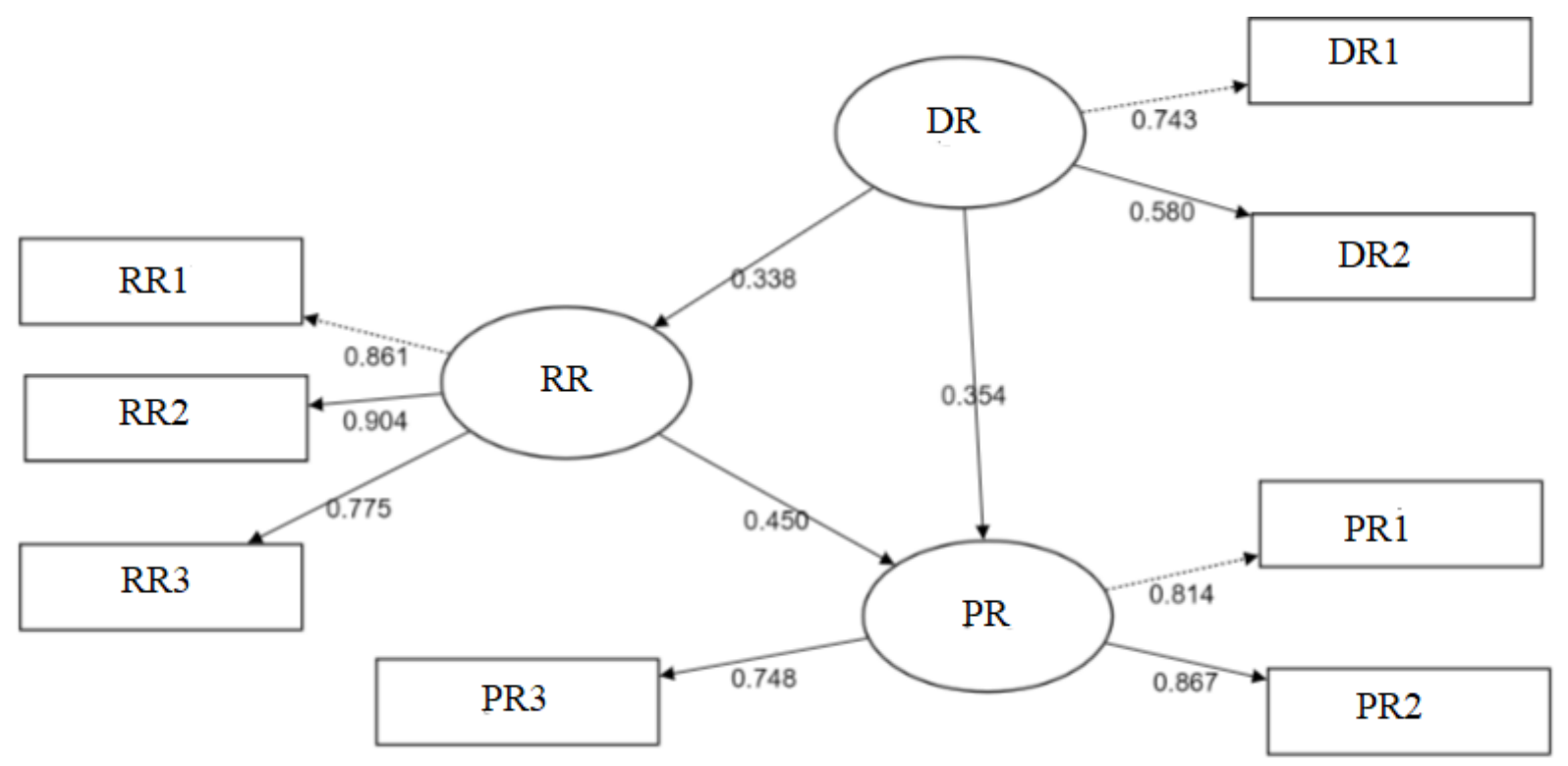

Figure 3: The SEM forecast model.

\section{ANN-BASED SIMULATION}

The ANN is made up of many widely connected nodes. The topology of the network mainly refers to the connection method of the nodes. By topology, the ANN can be divided into two categories: hierarchical network, and interconnected network [33]. The ANN was adopted for simulation, because its structure is similar to the relationship between the nodes in manufacturing supply chain.

With 4 nodes in the hidden layer, the BPNN was trained for 100 times on 20 samples. Table VII presents the training results. The simulation results are provided in Fig. 4.

Table VII. Training results.

\begin{tabular}{|c|c|c|c|c|}
\hline Number & Predicted value & Actual value & Absolute error & Relative error \\
\hline 1 & 2.2250 & 2.2009 & 0.0241 & 0.0110 \\
\hline 2 & 3.1518 & 3.3465 & 0.1947 & 0.0582 \\
\hline 3 & 1.8749 & 1.6979 & 0.1771 & 0.1043 \\
\hline 4 & 2.3474 & 2.3554 & 0.0080 & 0.0034 \\
\hline 5 & 2.8389 & 2.8424 & 0.0034 & 0.0012 \\
\hline 6 & 2.4626 & 2.4711 & 0.0085 & 0.0034 \\
\hline 7 & 2.2709 & 2.2521 & 0.0188 & 0.0083 \\
\hline 8 & 2.3322 & 2.3450 & 0.0128 & 0.0054 \\
\hline 9 & 2.0168 & 1.9861 & 0.0306 & 0.0154 \\
\hline 10 & 2.6835 & 2.6868 & 0.0032 & 0.0012 \\
\hline 11 & 2.7526 & 2.7659 & 0.0133 & 0.0048 \\
\hline 12 & 2.6787 & 2.6902 & 0.0115 & 0.0043 \\
\hline 13 & 2.9265 & 2.9069 & 0.0196 & 0.0068 \\
\hline 14 & 3.1623 & 3.3440 & 0.1817 & 0.0543 \\
\hline 15 & 2.3260 & 2.3230 & 0.0030 & 0.0013 \\
\hline 16 & 2.6314 & 2.6266 & 0.0048 & 0.0018 \\
\hline 17 & 2.9482 & 2.9220 & 0.0262 & 0.0090 \\
\hline 18 & 2.2135 & 2.1786 & 0.0349 & 0.0160 \\
\hline 19 & 2.0148 & 1.9890 & 0.0258 & 0.0130 \\
\hline 20 & 2.2099 & 2.2096 & 0.0002 & 0.0001 \\
\hline
\end{tabular}




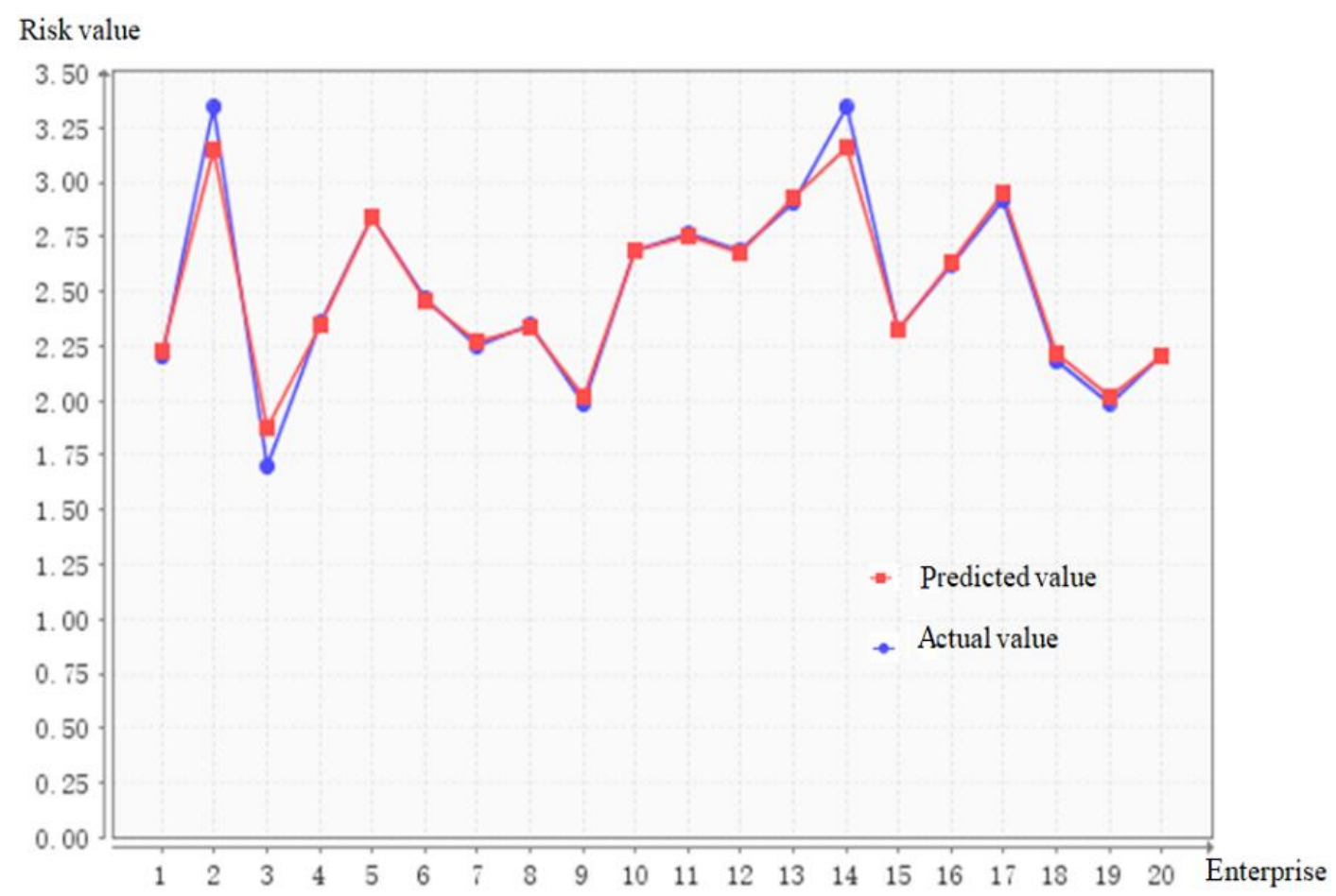

Figure 4: Simulation results.

As shown in Table VII and Fig. 4, the predicted value almost coincided with the actual value, indicating that the risk forecast model (Fig. 3) is suitable and practical.

\section{CONCLUSIONS}

The management of supply chain risks provides a way for enterprises to enhance efficiency and core competitiveness. But any supply chain, however safe or reliable, face a variety of risks in actual operations. If these risks are not identified and controlled, the supply chain management will threaten enterprise operations, rather than create benefits.

To solve the problem, this paper identifies the risk sources and indices of the manufacturing supply chain in China, and carries out SEM on risk forecast based on the data of a questionnaire survey. Through theoretical analysis and empirical simulation, the proposed risk factors and indices were proved reasonable, and the relevant hypotheses were verified in turn.

More innovatively, this research suggests that the market demand risk is the most fundamental risk factor of the supply chain, and the inducer of other supply chain risks. Moreover, the relationship risk was found to have an intermediary effect. In the supply chain risk management, it is necessary to promptly follow the changes in the external market environment to make some strategic challenges, but also pay attention to the management of the supply chain relationship structure. Therefore, the supply chain risks should be managed according to the changes in the external market environment, as well as those to the structure of the supply chain.

\section{REFERENCES}

[1] Wang, S. P. (2014). Research on Risk Control of Manufacturing Supply Chain Under the Condition of Uncertain Demand, Master Thesis, Beijing Jiaotong University, Beijing, doi:10.7666/d.Y2603431

[2] Jin, N. (2011). Research on risk identification method of supply chain based on inherent safety, Chinese Safety Science Journal, Vol. 21, No. 3, 145-149, doi:10.3969/j.issn.10033033.2011.03.025 
[3] Neiger, D.; Rotaru, K.; Churilov, L. (2009). Supply chain risk identification with value-focused process engineering, Journal of Operations Management, Vol. 27, No. 2, 154-168, doi:10.1016/j.jom.2007.11.003

[4] Wang, J.-M.; Zhang, K.-Y. (2011). Risk assessment of supply chain system based on extension matter element model, Science Technology and Industry, Vol. 11, No. 5, 49-53, doi:10.3969/j.issn.1671-1807.2011.05.012

[5] Xu, Y.; Tian, H. C. (2004). Application of VAR model in supply chain risk control, Statistics and Decision, Vol. 2004, No. 10, 46-47, doi:10.3969/j.issn.1002-6487.2004.10.024

[6] Peng, G.-L.; Yao, J. (2010). Fuzzy comprehensive evaluation based on uncertainty in supply chain risks, Journal of University of Shanghai for Science and Technology, Vol. 32, No. 4, 373-377, doi:10.3969/j.issn.1007-6735.2010.04.016

[7] Zhang, Y.-B.; Chen, J.-F. (2008). The risk identification framework of supply chain and its flexible control strategy, Industrial Engineering and Management, Vol. 13, No. 1, 47-52, doi:10.3969/j.issn.1007-5429.2008.01.010

[8] Thun, J.-H.; Hoenig, D. (2011). An empirical analysis of supply chain risk management in the German automotive industry, International Journal of Production Economics, Vol. 131, No. 1, 242-249, doi:10.1016/j.ijpe.2009.10.010

[9] Wang, H.; Han, R. Z.; Zhao, L. D. (2008). Supply chain system risk measurement based on ES model, Statistics and Decision, Vol. 2008, No. 8, 10-12

[10] Jiang, Y. L.; Yang, J. Q.; Yin, L. Y.; Yang, J. (2008). ANN-based comprehensive evaluation model of supply chain risk and its application, Journal of Wuhan University of Technology (Transportation Science and Engineering), Vol. 32, No. 1, 70-73, doi:10.3963/j.issn.2095$\underline{3844.2008 .01 .019}$

[11] Pan, M.; Zhang, J. T.; Chen, X. D.; Du, J. (2019). A study on risk assessment of automotive supply chain based on neural network, Shanghai Management Science, Vol. 41, No. 1, 99-106, doi:10.3969/j.issn.1005-9679.2019.01.017

[12] Janekova, J.; Fabianova, J.; Fabian, M. (2019). Assessment of economic efficiency and risk of the project using simulation, International Journal of Simulation Modelling, Vol. 18, No. 2, 242-253, doi:10.2507/IJSIMM18(2)467

[13] Macbeth, D. K.; Ferguson, N. (1994). Partnership Sourcing: An Integrated Supply Chain Management Approach, Financial Times, London

[14] Ma, X. M. (2018). Research on trust mechanism and risk prevention of supply chain partnership, Market Modernization, Vol. 2018, No. 4, 19-21, doi:10.14013/j.cnki.scxdh.2018.04.007

[15] Tang, P. Q. (2012). Research on Supply Chain Cooperative Relationship Risk Management of Automobile Manufacturing Enterprises, Master Thesis, Nanchang University, Nanchang, doi:10.7666/d.y2141089

[16] Zhang, R. (2014). Empirical Research on the Relationship Between External Environment, Reverse Supply Chain Management Implementation and Organizational Performance, Jiangsu University, Zhenjiang, doi:10.7666/d.Y2538242

[17] Song, Y.-T.; Su, Q.; Li, Z.; Dang, J.-X. (2009). The impact of supply chain relationship on cooperative behaviors: an empirical investigation from manufacturing firms in China, Forecasting, Vol. 28, No. 3, 27-33, doi:10.3969/j.issn.1003-5192.2009.03.005

[18] Zhang, M. M. (2014). Research on the Influence of Supply Chain Power on Innovation Performance, Master Thesis, Jilin University, Changchun

[19] Zhang, Z. (2007). Research on the Influence of Supply Chain Relationship Quality on Inter Firm Cooperation Performance, Master Thesis, Xi'an University of Technology, Beilin, doi: $10.7666 /$ d.y 1814447

[20] Xia, M.; Zhang, Z. (2012). Research on the influence of supply chain relationship quality on the successful development of new products, Economic Research Guide, Vol. 2012, No. 23, 179-181, doi:10.3969/j.issn.1673-291X.2012.23.077

[21] Fynes, B.; de Búrca, S.; Marshall, D. (2004). Environmental uncertainty, supply chain relationship quality and performance, Journal of Purchasing and Supply Management, Vol. 10, No. 4-5, 179190, doi:10.1016/j.pursup.2004.11.003 
[22] He, Y. J. (2020). Influencing factors and evaluation model of quality risks in intelligent manufacturing mobile supply chain, Journal Européen des Systèmes Automatisés, Vol. 53, No. 6, 953-961, doi: $10.18280 /$ jesa.530621

[23] Wang, W. S. (2008). Research on Product Quality Risk Control in Supply Chain, Master Thesis, Nankai University, Tianjin, doi:10.7666/d.J0033169

[24] Jiang, J. D.; Zhao, H. P.; Feng, Y. C. (2008). Study on the features and modes of quality risk in supply chain, Chinese Journal of Management, Vol. 4, No. z1, 17-23, doi:10.3969/j.issn.1672$\underline{\text { 884X.2007.z1.005 }}$

[25] Chen, Q.; Deng, L. F.; Wang, H. M. (2018). Optimization of multi-task job-shop scheduling based on uncertainty theory algorithm, International Journal of Simulation Modelling, Vol. 17, No. 3, 543-552, doi:10.2507/IJSIMM17(3)CO14

[26] Yao, Z.; Leung, S. C. H.; Lai, K. K. (2008). Manufacturer's revenue-sharing contract and retail competition, European Journal of Operational Research, Vol. 186, No. 2, 637-651, doi:10.1016/j.ejor.2007.01.049

[27] Yu, H.; Chen, J.; Yu, G. (2006). Managing wholesale price contract in the supply chain under disruptions, Systems Engineering - Theory \& Practice, Vol. 26, No. 8, 33-41, doi:10.3321/ j.issn:1000-6788.2006.08.004

[28] Klibi, W.; Martel, A. (2012). Scenario-based supply chain network risk modeling, European Journal of Operational Research, Vol. 223, No. 3, 644-658, doi:10.1016/j.ejor.2012.06.027

[29] Li, X. J.; Li, S. F.; Liu, S. N.; Liu, L. F.; He, D. J. (2020). A malicious webpage detection algorithm based on image semantics, Traitement du Signal, Vol. 37, No. 1, 113-118, doi:10.18280/ts.370115

[30] Jiang, W. X. (2020). A novel big data classification algorithm based on backpropagation neural network, Revue d'Intelligence Artificielle, Vol. 34, No. 2, 203-208, doi:10.18280/ria.340211

[31] Brown, M. L.; Kros, J. F. (2003). Data mining and the impact of missing data, Industrial Management \& Data Systems, Vol. 103, No. 8, 611-621, doi:10.1108/02635570310497657

[32] Reid, D. M.; Mackay, I.; Wilkinson, S.; Miller, C.; Schuette, D. G.; Compston, J.; Cooper, C.; Duncan, E.; Galwey, N.; Keen, R.; Langdahl, B.; McLellan, A.; Pols, H.; Uitterlinden, A.; O'Riordan, J.; Wass, J. A. H.; Ralston, S. H.; Bennett, S. T. (2006). Cross-calibration of dualenergy X-ray densitometers for a large, multi-center genetic study of osteoporosis, Osteoporosis International, Vol. 17, No. 1, 125-132, doi:10.1007/s00198-005-1936-y

[33] Chen, X. Y.; Chen, H. X.; Wang, C.; Kuang, H. F. (2018). Research on information security risk assessment based on BP neural network, Information \& Communications, Vol. 2018, No. 4, 165166, doi:10.3969/j.issn.1673-1131.2018.04.076 